\title{
VARIABLE CONDITIONS PRODUCE VARIABLE RESPONSES IN GTNP BREEDING BIRDS
}

\author{
MARTIN L. CODY \\ UNIVERSITY OF CALIFORNIA $\uparrow$ LOS ANGELES
}

\begin{abstract}
$\uparrow \quad$ ABSTRACT
Conditions in the GTNP breeding season can differ dramatically among years, even between adjacent years such as 2011 and 2012. Specifically, 2012 was the warmest and driest spring since the early 1990s, with snow melt-out date (SMOD) on April 17, a few days earlier than the long-term average, and $90 \%$ aspen leaf-out also earlier than the mean by nearly a week. In contrast, 2011 was the latest SMOD and aspen leaf-out in some $50 \mathrm{y}$. Birds settle in breeding habitat with somewhat altered preferences in early, warm and dry years such as 2012 compared to opposite conditions in the 2011. In 2012, many birds typical of lower, more open and less mesic habitats were found breeding in taller, denser and usually wetter habitats, a clear influence of the currently prevailing conditions in the park. A monitoring site of intermediate vegetation height and density, Site \#9: RKO Dry Willows, is used to calibrate these habitat shifts.
\end{abstract}

\section{$\downarrow \quad$ INTRODUCTION}

Late spring and early summer weather conditions can vary dramatically in Grand Teton National Park (GTNP) from one year to another, even in one year to the next. For example, 2012 was the warmest and driest spring since the early 1990s, with a relatively early snow melt-out date (SMOD) on April 17 , a few days earlier than the long-term average, and $90 \%$ aspen leaf-out make the same (as measured by an accumulated total of 125 growing degree-days -GDD$125)$ also earlier than the mean by nearly a week. Both GDD125 and SMOD are useful predictors of conditions available for breeding birds in GTNP, and together with spring temperatures (SPRT: average monthly temperature March-May) and spring precipitation (SPRP: total March-May inclusive) have a reasonably high predictive power for habitat occupancies and species shifts over habitat gradients as well as in-site breeding densities. In some circumstances, long-term census data can show that winter temperatures (those in December-February proceeding the breeding season) have an impact on breeding densities the following spring. In addition, for some longer-lived species, weather effects from seasons and years further back in time can influence habitat occupancy as well as breeding density. This report follows a previous summary account of local influences on breeding bird densities (Cody 2011).

\section{$\uparrow \quad$ METHODS}

Weather data used in this report are those collected from the weather station "Moran $5 \mathrm{~N}$ " by Larry Robinson near the Jackson Lake Dam; thanks to Larry for sharing his data and his further observations of birds and weather.

Bird census data from a dozen monitoring sites were collected annually by this author; census protocols for the monitoring program were specified at its initial establishment in the early1990's. One of the monitoring sites, Site \#9, termed "RKO Dry Willows," has been censused each year since 1993, 2012 being the $20^{\text {th }}$ year in the sequence. The site is particularly appropriate for examining the effects of variable on-site conditions for breeding birds, as it can vary conspicuously among years e.g. from extremely wet to quite dry; see below for details. 


\section{$\downarrow \quad$ RESULTS}

\section{Overall Range of Spring Weather}

Events that signal spring or its approach are known to be unpredictable in GTNP; examples of variability that are marked on the calendars of many Jackson Hole residents depicting the date of melt-out of the winter snows, and the dates of leaf-out in the deciduous trees. Elsewhere at northern latitudes, the dates of lilac or cherry tree blooms or the return of cuckoos from southern wintering grounds serve as similar indicators of the advance of the seasons. These indirect measures of the approach of spring are in turn the product of actual spring temperatures and/or precipitation, and in the case of snow melt-out due also to the amount of winter precipitation. A principle component (PC) analysis of these weather variables, indirect and direct, is shown in Figure 1 and illustrates the resultant range of conditions that is experienced in GTNP over a couple of decades.

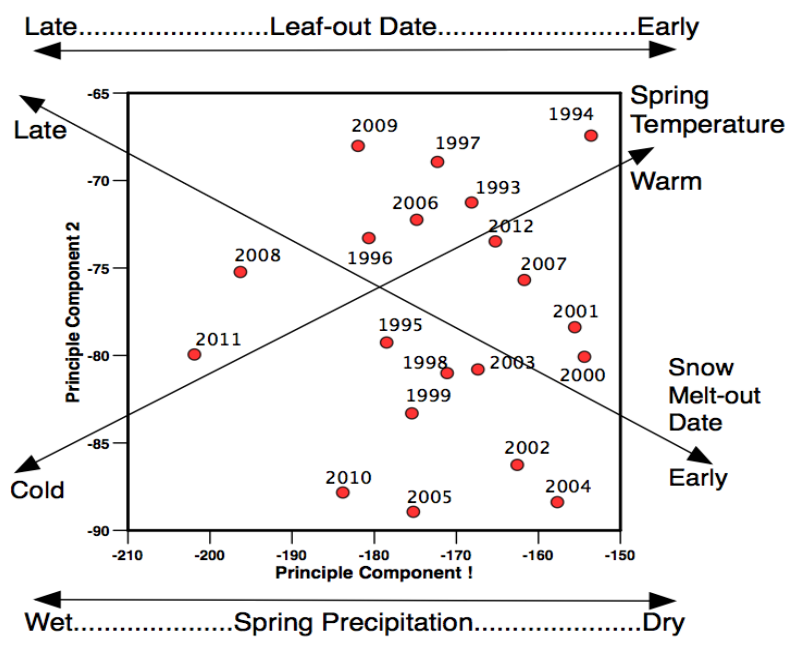

Figure 1. Principle component plot illustrating variability in spring weather conditions in GTNP.

The components are correlated to measured variables of spring precipitation and temperature, leafout and snow melt-out dates, as shown by the arrowheaded vectors. Note that adjacent years such as 20092010 or 2011-2012 can be quite different in these values. In considering the variation in weather between adjacent ( $\mathrm{t}-1)$, sub-adjacent $(\mathrm{t}-2)$ and older ( $\mathrm{t}$ $3, t->3$ ) years, it appears that there is no signal among years in SPRT or in GDD125, but there is: a) a weak but notable tendency for SPRP to show contrasts between adjacent years (e.g. alternating high-lowhigh-low), and b) for SMOD to show similar values over a series of three (but not four) years.

\section{Monitoring Site \#9: "RKO Dry Willows"}

The RKO monitoring site lies alongside the Snake River, and is marked by a series of parallel swales and crowns, parallel to each other and parallel to the present course of the Snake River, clearly the product of bygone river edge activity and of bank recontouring. The swales are around a meter or so lower than the crowns and ca. $100 \mathrm{~m}$ apart. The lower swales can collect and retain water to a depth of several feet and support marshy vegetation bordered by willows. The crowns are topped by low and open vegetation dominated by Great Basin sagebrush (Artemisia tridentata), and so represent a semi-desert vegetation in diametric contrast to the swales. In wet springs when the Snake River in running high, its banks directly overspill into this site, and part of the downriver runoff is through the site along the swales. In dry years one can walk through the site dry-shod when the marshy swales are constricted to narrow and muddy ecotones.

\section{Responses of Specific RKO Breeding Birds}

In 2012, birds generally more prevalent in drier and lower habitats, were present in higher abundance in the RKO whereas birds generally typically of taller woodland and forest were less prevalent there. Further, two bird species were recorded at the RKO in 2012 for the first time in $>20$ $\mathrm{y}$ of its monitoring: i. Lazuli Bunting Passerina amoena, a bird of open scrubby hillsides and a species that is fairly common elsewhere in the park, and ii. Yellow-breasted Chat Icteria virens, a species not seen by the author at any time in the park during the preceding $50 \mathrm{y}$, and a species typical of the drier shrubby habitats fringing the Great Basin Desert (in the West), or a species of early successional scrub vegetation (in the East).

The four most abundant breeding emberizines at this site are Song, Fox, Lincoln's and White-crowned Sparrow. The years in which these species reach or exceed 1 standard deviation (SD) above their mean densities at the site are illustrated by the highlighted blobs (Figure 2). In 2012 Lincoln's Sparrow was recorded at the highest densities (5.5 pr., 2.2 $\mathrm{SD}>$ mean) since monitoring began in 1993 . White-crowned Sparrow was also common in 2012 (3 pr., 0.70 SD > mean), but Song Sparrow and Fox Sparrow were both present at below-average densities ( $3,1.13$ pr. respectively). The former is most common after relatively cool, wet and late spring seasons, whereas Fox Sparrow reaches its maximum density (2.3 SD > mean) in 2011, which was the ultimate in cool, wet and late spring seasons. 


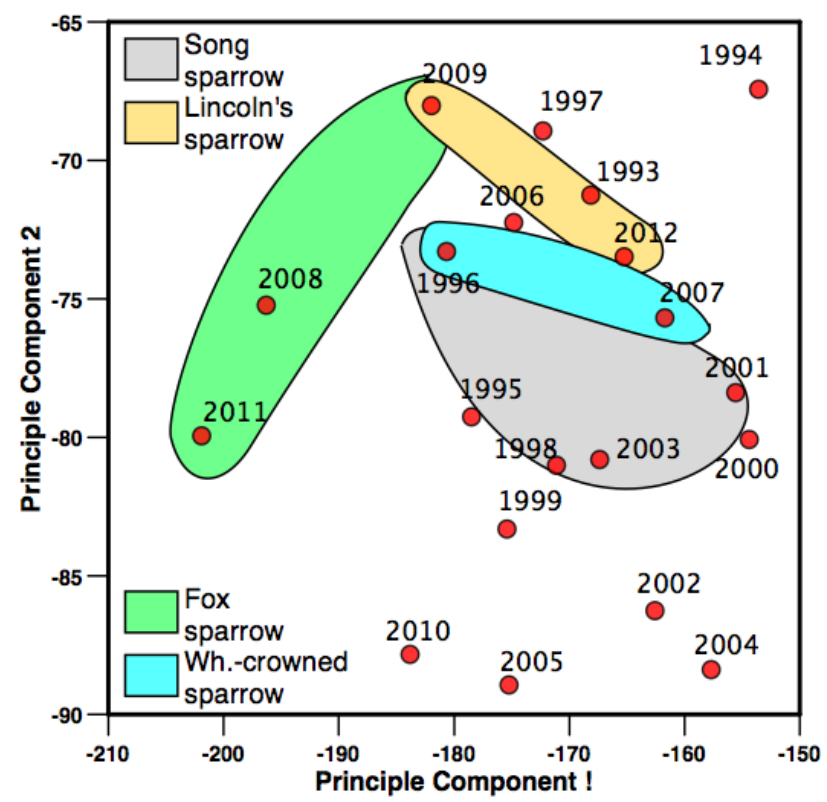

Figure 2. The four commonest breeding emberizine sparrows at the RKO site reach their highest breeding densities in generally quite different years.

Of the RKO breeding birds discussed here, only the Song Sparrow is close to being a resident species; the others engage in short- or long-distance migrations. In view of this distinction, it may not be surprising that only Song Sparrow RKO breeding densities appear to be influenced by preceding winter temperatures. Correlation coefficients with years $t-1$, $\mathrm{t}-2$ and $\mathrm{t}-3$ winter temperatures are $0.54^{*}, 0.32$ and 0.18 respectively $(*$ signifies $\mathrm{p}<0.05$ ); thus Song Sparrows apparently survive local winters better in warmer than in colder years, and settle in breeding densities in part reflecting that improved survival.

Amongst the less common breeding emberizines at the RKO site are Green-tailed Towhee and Brewer's Sparrow, both typical species of the Great Basin desert sagebrush-dominated regions of the west and southwest (Figure 3). The former nested at this site with greater than a marginal presence only in the two warmest and driest years, 1993 and 1994 (at 3.7 and $1.7 \mathrm{SD}>$ mean). The latter reached its highest ever density in 2012 (3.3 SD > mean), although it was fairly common also in 2001, another early, dry year. Vesper Sparrow, in contrast, is present in cool, wet years; in 1995, which was the second-wettest spring (after 2011) it reached its highest breeding density of 0.5 pr. (2.9 $\mathrm{SD}>$ mean).

Two Empidonax flycatchers are common breeding birds at the RKO site, although a third species (E. minimus) is occasionally present also. As shown

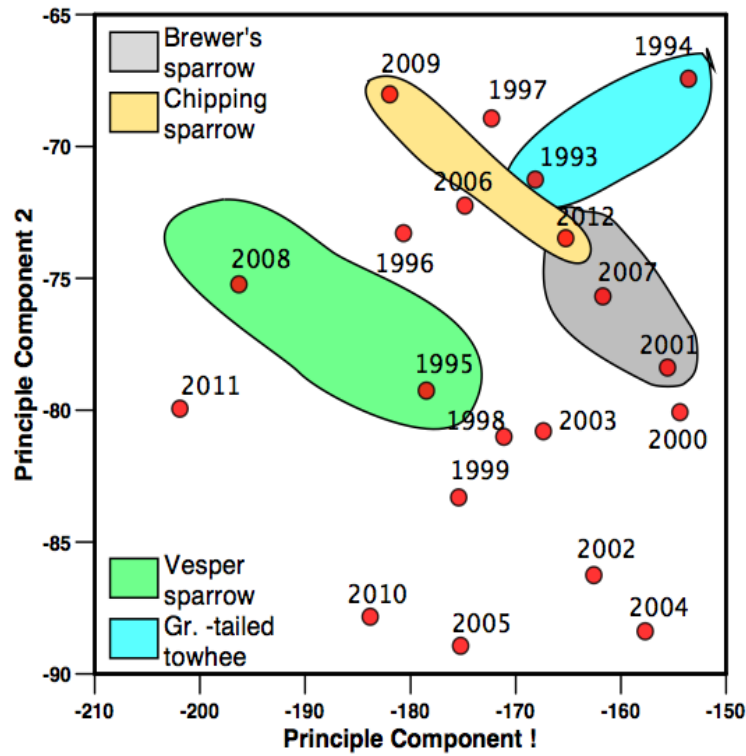

Figure 3. The distributions (over years) in which four less common emberizines reach high breeding densities at the RKO monitoring site.

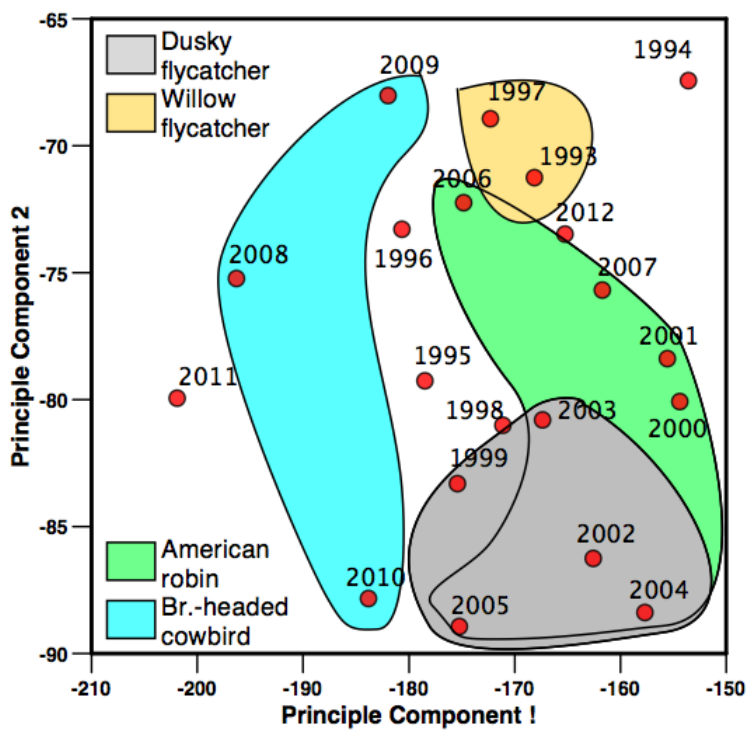

Figure 4. Years in which four common breeding RKO birds, two flycatchers, robin and cowbird, reached their highest breeding densities.

in Figure 4, the two common flycatchers respond to quite different local conditions in terms of breeding densities, with Willow Flycatchers especially common in early, cool and dry years, and Dusky Flycatcher at high densities in warmest, dry years. Over the 20-y census period, Dusky Flycatcher has averaged some $1.8 \mathrm{pr}$. at the site, Willow Flycatcher somewhat less at 1.1 pr. AsWillow Flycatcher is associated with willows and wet sites in general, it would appear contradictory that its RKO densities are not highest in 
wet years. In fact, this species is commonest in drier springs that follow wet winters (correlation with WINP: $0.64 * *$; WINP-1: 0.46, WINP-2: 0.22 , a response that has carryover effects from previous years' winter precipitation** signifies $\mathrm{p}<0.01$ ). American Robin is common at practically all second principle components (PCII) values, but only at high first principle component (PCI) values that indicate early and warm spring conditions. The opposite conditions characterize Brown-headed Cowbird densities, highest at low PCI values, for reasons not readily apparent to this author.

Four species of paruline warblers breed at the RKO monitoring site, one commonly, one routinely but at low density, and two others occasionally. Yellow Warbler is present at much higher densities (20-y ave. 9.9 pr) than Common Yellowthroat (ave. 3.4

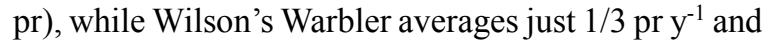
MacGillivray's Warbler only $1 / 10$ pr $\mathrm{y}^{-1}$. The distributions over years of high density are shown in Figure 5 for Yellow Warbler and Common Yellowthroat, in which it appears that neither species benefits or responds to the more extreme weather conditions, but each species is commoner in relatively average years. Warbling vireo is casual at this site (present in 4/20 years), and the three years of its higher densities (which include 2012) coincide with those of the earliest onset and the warmest of springs. Gray Catbird has a similar incidence at Site \#9 as Warbling Vireo, but catbirds reached high density (of $3.8 \mathrm{SD}>$ mean) in just a single year, 2009. As 2009 does not show up as a distinct year in any of the variables we have discussed-SPRT, SPRP, SMOD, GDD125-it is likely that catbird density is regulated by off-site rather than on-site factors.

\section{Carryover Effects of Climate Variation}

Some instances have been mentioned above in which RKO breeding bird densities appear to reflect weather conditions from previous years, rather than or as well as conditions in the current breeding year. In a number of cases there are statistically significant effects of weather variables on density from one or two years preceding the year of the density measurements. These are reported in Table 1; values at the $\mathrm{p}<0.01$ level are shown in boldface.

The values in the table confirm, in general, relationships already highlighted above; others make sense with the advantage of hindsight. For example, many more species are responsive to conditions the previous year than those in the present year. This implies that, rather than current conditions at the

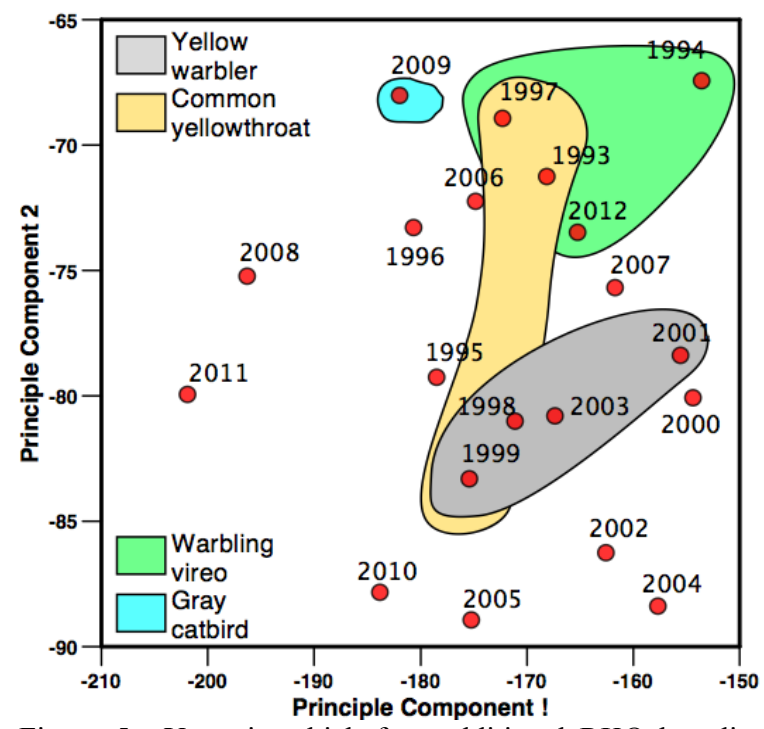

Figure 5. Years in which four additional RKO breeding species, two of them regular breeders (the warblers) and two not, reached high densities of over $1 \mathrm{SD}>$ mean density.

Table 1. Years in which four additional RKO breeding species, two of them regular breeders (the warblers) and two not, reached high densities of over1 SD $>$ mean density.

\begin{tabular}{|c|c|c|c|c|c|c|c|c|}
\hline Table 1 & & & & & & & & \\
\hline Species/variable & PCI & PCII & SPRT & SPRP & SMOD & $\mathrm{GDD}^{125}$ & & \\
\hline PCI & & & 0.44 & -0.61 & & \begin{tabular}{|l|} 
\\
\end{tabular} & & \\
\hline PCII & & & 0.50 & & & -0.67 & & \\
\hline \multicolumn{9}{|l|}{ Song Sparrow } \\
\hline Fox Sparrow & -0.52 & & & 0.44 & 0.61 & & & \\
\hline Brewer's Sparrow & & & & -0.44 & & & & \\
\hline BI.-headed Grosbeak & & -0.46 & & & & & & \\
\hline Dusky Flycatcher & 0.46 & & & & -0.55 & & & \\
\hline Gray Catbird & & 0.44 & & & 0.47 & & & \\
\hline Warbling Vireo & & & 0.53 & & & -0.51 & & \\
\hline \multirow[t]{3}{*}{ Br.-headed Cowbird } & & & & -0.44 & & & & \\
\hline & SPRT & SPRP & SMOD & $\mathrm{GDD}^{12}$ & SPRT & SPRP & SMOD & $\mathrm{GDD}^{125}$ \\
\hline & -1 & -1 & -1 & -1 & -2 & -2 & -2 & -2 \\
\hline Fox Sparrow & & & 0.45 & & & & & \\
\hline Lincoln's Sparrow & & & 0.59 & & & & & \\
\hline Chipping Sparrow & & 0.46 & 0.67 & 0.53 & & & & \\
\hline Savannah Sparrow & 0.65 & & & -0.50 & & & & \\
\hline Gr.-tailed Towhee & 0.70 & & & -0.62 & & & & \\
\hline Lazuli Bunting & & 0.50 & 0.47 & & & & & \\
\hline Dusky Flycatcher & & & -0.48 & & & & -0.49 & \\
\hline American Robin & & & & & -0.59 & & 0.57 & 0.54 \\
\hline Gray Catbird & & & 0.57 & & & & & \\
\hline Common Yellowthroat & & & & -0.52 & & 0.50 & & \\
\hline MacGillivray's Warbler & & 0.48 & & 0.47 & -0.49 & & & \\
\hline Br.-headed Cowbird & -0.62 & & & & & & & \\
\hline
\end{tabular}

RKO site, some breeding densities are attributable to successful reproduction in the previous year. In the case of American Robin, the largest are likely the longest-lived of those species listed, and it is conditions two years prior to the present that best predict the present robin breeding densities. Additionally in the case of Common Yellowthroat, whose territories are centered on the wet, marshy areas on the site, it is precipitation two years previously that best determines present breeding densities. These results in turn make most sense in that there is a reasonably high degree of philopatry in the GTNP breeding birds. 


\section{$\downarrow \quad$ Literature CiTED}

Cody ML. 2011. Influence of Spring Weather Conditions on Breeding Bird Densities in GTNP. In: Harlow HJ, Harlow MA editors. UW NPS Research Station Annual Report. 34:33-38. 